\title{
The Assessment Process of Learning Difficulties: Designing a Non-Standardized Assessment Test for Adolescents
}

\author{
Kalliopi Papoutsaki ${ }^{1} \quad$ Eleni Marseli ${ }^{2} \quad$ Johan Papathansiou $^{3}$ \\ 1. National Kapodistrian University of Athens, Kidathineon, 53, Helioupis, 15566, Athens, Greece \\ 2. Special Education Teacher, Dexamenis 42, Metamorfosi, 14452, Athens, Greece \\ 3. Philologist, Kidathineon, 53, Helioupis, 15566, Athens, Greece \\ * E-mail of the corresponding author: kpapouts@primedu.uoa.gr
}

\begin{abstract}
This article presents the process of the assessment and a non-standardized test which was designed by special teachers working at a Public Centre for Diagnosis of Adolescents' Learning Difficulties in Greece. This diagnostic test for learning difficulties (DTLD) is based on the Greek curriculum and aims at identifying the student's cognitive and learning deficiencies by assessing their cognition in listening, speaking, reading, spelling, writing and maths. We use it to determine the type of learning difficulties in combination with standardized tests. We take the results of the assessment test (DTLD) into account in conjunction with the reports from the school teachers, speech therapists, psychologists, social workers and psychiatrists to clearly understand adolescents' deficiencies. Furthermore, questionnaires and interviews are applied to parents and adolescents in order to help experts to understand students' educational profile, which is substantial to the assessment. As a result, the above procedure assists diagnostic evaluation and reveals the cognitive and socio-emotional profile of each student, which can then be used by the multidisciplinary team to propose the structure of the appropriate educational program and interventional techniques. Moreover, the test axes are designed by the authors based on learning difficulties literature so the assessment test (DTLD) can be used by school teachers to identify adolescents' deficiencies and to create early and tailor-made interventions depending on the particular needs and educational deficiencies of each student.
\end{abstract}

Keywords: assessment, learning difficulties, assessment test

DOI: $10.7176 / \mathrm{JEP} / 11-20-01$

Publication date:July $31^{\text {st }} 2020$

\section{Introduction}

Given learning difficulties complexity, it is worth evaluating learning disabilities of a multidisciplinary team of experts (Hayes, Dombrowski Shefcyk, \& Bulat, 2018). Effective evaluations should assess all areas related to a student's suspected disability, including: health, vision and hearing, social and emotional status, general intelligence, academic performance, communication abilities, and motor skills (Farrall, Wright, \& Wright, 2015). A multidisciplinary evaluation is carried out by specialists such as doctors (pediatrician, pediatric psychiatrist, otorhinolaryngology, ophthalmologist), a social worker, a psychologist, a speech therapist and a special educator. Thus, it creates a well-rounded diagnostic approach that highlights the development of the student's social; psychometric; psychological profile; as well as the oral speech and level of learning.

Identifying children's difficulties from different scientific disciplines contributes to appropriate intervention programs designed by specialists to support pupils in their successful integration in mainstream schools (Fletcher, Lyon, Fuchs \& Barnes, 2006). Assessments by Diagnostic Centres and multidisciplinary teams are conducted through structured or semi-structured interviews and the administration of clinical tests. Thereafter, each evaluator will compose a report that will lead to an informed diagnostic and individualized assessment.

Learning assessments aim at identifying the degree of pupils' difficulties either through an initial evaluation that simply reveals the existence of difficulties or through a secondary evaluation that specifies the areas presenting deficits and how these affect school performance (Hayes, Dombrowski, Shefcyk, \& Bulat, 2018). First, teachers detect if there are any issues of learning difficulties and afterwards they use their programs like Response to Intervention (RtI) to support adolescents with learning difficulties. Nevertheless, if learning difficulties continue to appear, they urge children to go to Public Diagnostic Centers so that they can be identified by multidisciplinary teams. Parents' involvement is also important for the identification of learning difficulties (Rutland \& Hall, 2013), especially when information is provided by expert guidance. Learning Disabilities' diagnosis from teachers or the interdisciplinary team can be done by using standardized and nonstandardized tests, as mentioned below.

Unfortunately, there are not enough standardized tests in Greece, especially when it comes to assessing adolescents. In addition, only few educators have been trained and are qualified to conduct such tests. Some of them are (Tzivinikou, 2015): a) "Lambda test", which is a special software that detects specific learning difficulties, in producing and acquiring writing, spelling, reading, comprehension, vocabulary, working memory and speech for pupils of 10-15 years old. b) Identification of Learning Disabilities by Teachers (I.L.D.T), which 
investigates the existence of learning difficulties for pupils 8-15 years old, speaking; writing; reading; maths, c) $\mathrm{A}^{\prime}$ Test, which detects reading errors from 8-15 year old pupils; d) The Detroit Learning Proficiency Test, which is used to assess pupils' proficiency from 4-19 years of age and investigates articulation, concept association, number sequences, memory, etc. Although these tests are being used, experts create a series of non-standardized assessment tests to detect pupils' learning deficiency and design appropriate interventions.

In the existing international literature, there is a number of standardized and non-standardized protocols of evaluations that focus on visual and auditory perception; the educational environment; learning difficulties including disorders in reading and writing; and the ability to handle new technologies so that they can be used in interventions (Hayes, Dombrowski, Shefcyk, \& Bulat, 2018). Furthermore, some well-known tests for diagnosing a learning disability are the Woodcock-Johnson Tests of Achievement (WJ), the Wechsler Individual Achievement Test (WIAT), the Wide Range Achievement Test (WRAT) and the Kaufman Test of Educational Achievement (KTEA). These tests focus on evaluating reading, writing, and maths.

Both standardized and non-standardized tests can be used as part of a learning assessment. Standardized assessment tests ensure reliability, validity and objectivity of results because large data samples are collected and a set of structured rules follows for administration and scoring. Nevertheless, no-standardized assessment tests of learning difficulties are designed by special education teachers in order to identify learning dysfunctions. Furthermore, in Greece these tests are usually based on the National Curriculum in relation to age cognition, the peculiarities of language and the existing knowledge by evaluating (reading, writing, vocabulary, maths etc.). By combining standardized with non-standardized tests, more reliable conclusions and valuable suggestions to teachers may support students in their difficulties in a better way.

The purpose of this study is to present the process of evaluation that takes place in a Greek Public Centre for Adolescents' Diagnosis in Learning Difficulties. Then, it presents the non-standardized assessment test (DTLD) that identifies adolescents' learning difficulties from 11 to 18 years of age. It focuses on adolescents' deficiencies in reading, spelling, writing and maths, in order to identify the type of learning difficulty and it proposes the appropriate educational program.

\section{Multidisciplinary evaluation}

Multidisciplinary evaluation is the type of evaluation adopted by all diagnostic and learning assessment centers. Each student's file contains their medical, social, psychological and pedagogical profile which is formed by a teenage medical doctor, a social worker, a psychologist and a special educator, who are working in the Centre. The Wechsler Intelligence Scale for Children-III (WISC-III) is used by the specialized psychologist to diagnose children's Intelligence Quotient and learning deficiencies. It is also used as an executive function task measure. In addition, vision and hearing screening is checked by specialists. Speech therapists evaluate speech abilities, whilst special educators assess learning difficulties. Furthermore, information is obtained from progress reports made by teachers, grade point average reports and school exams. The multidisciplinary team meets after the completion of their evaluations in order to exchange information and thus formulate suggestions that could benefit both parents and the school.

\section{Pedagogical evaluation}

Initially, the special educator receives the adolescent's educational background from interviewing parents and by evaluating the adolescent with a semi-structured interview. In addition, teachers' reports, student's profile, school grades, literacy and maths exams, and prior evaluations from private or public entities are taken into account. Moreover, standardized and non-standardized assessment tests evaluate students' reading, spelling, writing and maths skills by a special education teacher.

\subsection{Teacher reports}

School's teachers are obligated to complete a questionnaire, which outlines the students' pedagogical background, school integration, behavior, abilities and problems identified in the school context. Teachers' reports, school grades and performance tests will also be taken into account.

\subsection{Designing the pedagogical background}

A very important source of information is collected from students and their parents. The examiner is trying to create a positive atmosphere with parents. The topics discussed refer to the school context and how students manage to integrate, the relationship with both teachers and other classmates, their family norms and dynamics, the timing and way of identifying difficulties and their coping methods and techniques. Students' social network, peer relationships, interests, and extracurricular activities are also considered.

In addition, the examiner is trying to create a positive atmosphere, a comfortable and peaceful environment without disruptive factors which will result in a positive dialogue between the adolescent and him. The dialogue between adolescent and teacher is related with his personal life concerning friendships, family relationships, 
interests, school environment such as school performance, strengths and weaknesses, and intervention techniques that have already been used by himself or through his school in order to cope with his difficulties. The interview highlights the adolescent's basic personal characteristics and communication skills because all these influence their learning according to recent research (Angelkoska, Stankovska \& Dimitrovski, 2016). Indicative topics for discussion are: pupils' experience from elementary transition to secondary education. Moreover, the school context, the difficulties with teachers, classmates, friendships, interests, ambitions, future plans, family and sibling relationships are also discussed. Each answer will be taken into account in the multidisciplinary meeting following the completion of the evaluation process. The examiner records the results of the evaluation on a fivepoint scale from low to high (1-5) (Table 1). The asterisk is the reverse score. We add up and multiply the grades by 100 . The score that is below $50 \%$ indicates deficiency.

Table 1. Communication skills and personal characteristics

\begin{tabular}{|l|l|l|l|l|l|l|l|}
\hline & \multicolumn{1}{|l}{} & 1 & 2 & 3 & 4 & 5 & Comments \\
\hline 1.1 & Visual Contact & & & & & & \\
\hline 1.2 & Cooperation with the examiner & & & & & & \\
\hline 1.3 & Pay Attention & & & & & & \\
\hline 1.4 & Focus on the subject & & & & & & \\
\hline 1.5 & Start a discussion & & & & & & \\
\hline $1.6^{*}$ & Impulsive & & & & & & \\
\hline $1.7^{*}$ & Shy & & & & & & \\
\hline 1.8 & Self-perception & & & & & & \\
\hline 1.9 & Learning motivation & & & & & & \\
\hline 1.10 & Interests & & & & & & Sum of points (A)... \\
\hline
\end{tabular}

* Reverse score

Total score:( A/50).100=..

\subsection{Assessment of learning difficulties}

The identification and evaluation of learning difficulties is facilitated by the use of standardized clinical scales and non- standardized improvisational tests. The designed non- standardized test (DTLD) described below aim at helping educators shape an objective view about adolescents' learning strengths and weaknesses. The Greek language and Greek Culture are taken into account. At first, the themes of the evaluation are designed, and then relevant tests related to each sub-scale of the tool follow. Next the axes of improvised informal assessment test are presented.

\section{Description of the axes of the informal evaluation test}

The main areas where students with learning disabilities experience failure and difficulty are reading, writing and mathematics (American Psychiatric Association, 2013). Oral, reading, writing, spelling, comprehension and mathematical skills are the main axes that are taken into account and will be discussed below.

The interview focuses on the adolescent's way of using his verbal speech and responding when someone is speaking to him. Oral language consists three major components: language form (vocabulary and syntax), semantics (narrative comprehension), and communicative competence. (Malec, Peterson \& Elshereif, 2017). The exam focuses on the vocabulary if it is poor or rich, the type of given answers, if he uses secondary sentences, the ability of description or storytelling and the flexibility of listening comprehension. During the interview the examiner records the results of the evaluation (Table 2).

\begin{tabular}{|l|l|l|l|l|l|l|l|}
\hline Table 2. Speech/Talk & 1 & 2 & 3 & 4 & 5 & Comments \\
\hline & & & & & & & \\
\hline 2.1 & Oral comprehension & & & & & & \\
\hline 2.2 & Fulfilled answers & & & & & & \\
\hline 2.3 & Selecting appropriate words & & & & & & \\
\hline 2.4 & Oral fluency & & & & & & \\
\hline 2.5 & Correct use of tenses & & & & & & \\
\hline 2.6 & Oral Vocabulary & & & & & & \\
\hline 2.7 & Syntactic structures & & & & & & \\
\hline 2.8 & Description use & & & & & & \\
\hline 2.9 & Narrative ability & & & & & & Sum of points (A)... \\
\hline 2.10 & Communicative competence & & & & & \\
\hline
\end{tabular}

Total score: $(\mathrm{A} / 50) \cdot 100=\ldots$ 
Reading skills require the activation of the cognitive system and a range of complex knowledge such as selective attention, eye focus, visual information retention of short memory (Nikolopoulos, 2007). Therefore, the evaluation focuses not only on the apparent difficulties, but also on their causes, in order to characterize the type of learning difficulties. Reading skills require acquisition of phonemic and phonological awareness, fluency, vocabulary and comprehension (Tzivinikou, 2015). Weak readers usually have difficulty in the speed and accuracy of the words they read. These dysfunction problems may negatively affect the comprehension dimension which is the main purpose of reading (Kim, Park, \& Wagner, 2014).

Adolescents read texts that have been chosen for them and which are related to their mental age in order to evaluate their reading skills. The reading evaluation is for the examinee to identify as letters; correct expression of phoneme, omissions, grammatical or syllable substitutions, distinction of letters or spelling. Nevertheless, speed at reading and comprehension are thoroughly checked during the examination as well. The adolescent reads words (real and false) and texts which range from 10 to 12 rows and are total around 100 words. Then they answer some questions to evaluate his ability of comprehension (Table 3 ).

Table 3. Reading Skills

\begin{tabular}{|c|c|c|c|c|c|c|c|}
\hline & & 1 & 2 & 3 & 4 & 5 & Comments \\
\hline 3.1 & Phonological Awareness & & & & & & \\
\hline 3.2 & Phonic decoding & & & & & & \\
\hline $3.3^{*}$ & Decoding of real words & & & & & & \\
\hline 3.4 & Decoding of false words & & & & & & \\
\hline $3.5^{*}$ & Monotony in reading (reading like a robot) & & & & & & \\
\hline 3.6 & Accuracy in Reading & & & & & & \\
\hline 3.7 & Correct use of punctuation & & & & & & \\
\hline $3.8^{*}$ & Unknown words & & & & & & \\
\hline $3.9^{*}$ & Unknown Phrases & & & & & & \\
\hline 3.10 & Comprehension & & & & & & \\
\hline 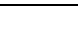 & Total score & & & & & & Sum of points(A). \\
\hline
\end{tabular}

* Reverse score

Total score: $(\mathrm{A} / 50) \cdot 100=\ldots$

Writing and spelling are skills that pupils learn at an early age and are some of the permanent learning factors (Duran \& Karatas, 2019). Students with writing difficulties make a lot of mistakes on simple words and grammar because it is very difficult for them to automate grammar rules. More severe dysfunctions are as follows: letters cannot be written correctly; mixing small and large letters; incomplete letters; writing the written manuscript in different directions; irregular letter shapes and sizes (Akyol, 2011), irregular space between letters and words, irregular size of the letters, letters are not aligned on the line (Graham, Santoro, Berninger \& Struck, 2006). All these dysfunctions affect legibility.

Teenagers write a text which is dictated and the examiner evaluates their writing skills, their speed of writing, and the pencil handling, (Table 4).

\begin{tabular}{|c|c|c|c|c|c|c|c|}
\hline & & 1 & 2 & 3 & 4 & 5 & Comments \\
\hline $4.1^{*}$ & Missing phonics/ syllables & & & & & & \\
\hline $4.2^{*}$ & Letter/syllable replacing & & & & & & \\
\hline $4.3^{*}$ & Mirror writing & & & & & & \\
\hline $4.4^{*}$ & Mixing small and large letters & & & & & & \\
\hline $4.5^{*}$ & Irregular letter shapes and sizes & & & & & & \\
\hline $4.6^{*}$ & Writing the written manuscript in different directions & & & & & & \\
\hline 4.7 & Illegible letters & & & & & & \\
\hline 4.8 & Using Space between letters and words & & & & & & \\
\hline $4.9^{*}$ & Slow writing time & & & & & & \\
\hline $4.10^{*}$ & Misuse pencil handling & & & & & & \\
\hline & Total score & & & & & & Sum of points $(\mathrm{A})$.. \\
\hline
\end{tabular}

* Reverse score

Total score: $(\mathrm{A} / 50) .100=.$.

Knowledge of grammar and syntax supports automatic dictation and writing skill mechanisms. Problems noted in a wide spectrum of writing skills include: (a) effectively organizing sentences and paragraphs; (b) writing clearly and precisely; (c) spelling correctly; (d) preparing concise, accurate, and supportive documents; (e) documenting work completely and accurately; (f) using correct grammar; (Jones, 2011). Students with dyslexia have difficulties recording their thoughts on paper and their text has many spelling mistakes. On the other hand, students with dysgraphia are characterized by difficulties in the acquisition of writing skills, (Döhla \& Heim, 2015). 
Evaluating the production of written speech with this informal tool is being done by developing a theme that is related to the examinees' mental age and personal experiences. It is valued by the structure of the development sentence related to the topic, paragraph consistency, text structure, vocabulary, writing appearance (Table 5). Grammar and syntax skills are evaluated compared with the errors of the Table 4 axes so that we can understand the type of difficulty (dyslexia or dysgraphia).

Table 5: Grammar and Syntaxes' Skills

\begin{tabular}{|c|c|c|c|c|c|c|c|}
\hline & & 1 & 2 & 3 & 4 & 5 & Comments \\
\hline 5.1 & Sentence structure & & & & & & \\
\hline 5.2 & Paragraph structure & & & & & & \\
\hline 5.3 & Textual development related to the topic & & & & & & \\
\hline 5.4 & Using correct grammar & & & & & & \\
\hline 5.5 & Using punctuation & & & & & & \\
\hline 5.6 & Enriched vocabulary & & & & & & \\
\hline 5.7 & Text style related to the communication context & & & & & & \\
\hline 5.8 & Spelling & & & & & & \\
\hline $5.9^{*}$ & Repetition on meanings & & & & & & \\
\hline \multirow[t]{2}{*}{5.10} & Writing appearance & & & & & & \\
\hline & Total score & & & & & & Sum of points(A).... \\
\hline
\end{tabular}

* Reverse score

Total score: $(\mathrm{A} / 50) .100=\ldots$

Students with maths difficulty demonstrate lower performance on counting tasks, arithmetic fluency and computation (Tolar, Fuchs, Fletcher, Fuchs, \& Hamlett, 2016), comparing quantities, word problem solving (Kingsdorf \& Krawec, 2014) and cognitive deficiencies (e.g., working memory, visual-spatial processing, or attention), (Fuchs et al., 2005). Their mathematical performance is below their age, intelligence, and education even though there are no conditions of intellectual disability, emotional disturbances, cultural deprivation, or lack of education (Büttner \& Hasselhorn, 2011). Evaluation of mathematical abilities may be done by solving exercises and practical arithmetic problems. Furthermore, understanding instructions, using correct mathematical symbols and time perception are also assessed, (Table 6).

Table 6. Maths' Skills

\begin{tabular}{|l|l|l|l|l|l|l|l|}
\hline & \multicolumn{1}{|l|}{ Table 6. } & 1 & 2 & 3 & 4 & 5 & Comments \\
\hline 6.1 & Visual-spatial processing & & & & & & \\
\hline 6.2 & Understanding maths language & & & & & & \\
\hline 6.3 & Number Sense and counting & & & & & & \\
\hline 6.4 & Sorting & & & & & & \\
\hline 6.5 & Computation & & & & & & \\
\hline 6.6 & Sequence of steps & & & & & & \\
\hline 6.7 & Correct use of symbols in maths & & & & & & \\
\hline 6.8 & Understanding instructions & & & & & & \\
\hline 6.9 & Problem Solving & & & & & & \\
\hline 6.10 & Time Perception & & & & & & \\
\hline & Total score & & & & & & Sum of points (A).... \\
\hline
\end{tabular}

Total score: $(\mathrm{A} / 50) .100=\ldots$

At the end of the assessment, the examiner observes and studies all the above axes and subscales, focusing on the adolescent's deficiencies and characterizes if the difficulty is related to educational deficiencies or learning difficulties. The examiner records the percentage and the types of errors on the five point scale from low to high (1-5). The total result is converted to a percentage score that shows weakness if the score is below $50 \%$, (Table 7).

Table 7. Total ppercentage of subscales

\begin{tabular}{|l|l|l|l|l|l|l|}
\hline & 1 & 2 & 3 & 4 & 5 & Percentage \\
\hline Communication skills and personal characteristics & & & & & & \\
\hline Speech & & & & & & \\
\hline Reading Skills & & & & & & \\
\hline Writing & & & & & & \\
\hline Grammar and Syntaxes' Skills & & & & & & \\
\hline Maths Skills & & & & & & \\
\hline
\end{tabular}

\section{The evaluation report}

The evaluation report is written when all experts have completed their assessments. Each assessment refers to the 
type of difficulties students face based on ICD10 (2015), such as Special Reading Disorder (F81.0), Special Spelling Disorder (F81.1), Specific Disorder of Arithmetic Skills (F81.2), Mixed Disorder in School Skills (F81.3). Afterwards, related therapies and ways to support students to cope with their difficulties within the family and school environment are suggested.

\section{Conclusion}

The assessment of learning difficulties by special private and public centres helps identify the areas of learners' deficiencies. A multidisciplinary team of experts observe the adolescents while interviewing, providing them with clinical examination, questionnaire, standardized and non-standardized tests. Standardized tests are difficult to use and take a long time because different ones are used to detect spelling, reading, writing, and maths difficulties. In addition, standardized assessments are frequently norm referenced, and they can assess the progress of all students in certain knowledge and skills (Bergeson, et al. 2008). The urgent need for assessment tests in secondary education in Greece is one more reason for designing the tool mentioned above. Taking the Greek standardized assessment tests of learning difficulties, the Greek Curriculum, the native language and Culture, we designed the Test (DTLD) in order to make it easy to use, fast and reliable. It is first used to determine the type of learning difficulty and then a standard assessment test is selected in order to focus more on the special difficulty. In this study we have presented only the axes because the items are related with the special language characteristics.

The goal is to assist teachers to evaluate adolescents' learning difficulties in different areas (speech, read, writing, maths), to identify the deficiencies, to design and implement customized intervention programs in classrooms or to create an Individualized Education Plan (IEP) for the student, as well as to determine what supports the student to succeed in school. An incomplete screening and evaluation process can lead to large rates of misdiagnosis, and students may not receive the services and supports they need to be academically successful. Hopefully, it is a valuable addition to the hands of both mainstream and special education teachers in order to be able to check their students' learning disabilities at first, and better support them to integrate appropriately in the school environment. Moreover, the test will be standardized through future research, so that the results will be more reliable and valid. After all, effective school integration is very important for adolescents as it facilitates their smooth transition to adult life and gives them a better understanding of the world and its mechanics (Scruggs, Mastropieri, Berkeley, \& Graetz, 2010).

\section{References}

Arai, T., Aiyama, Y., Sugi, M. \& Ota, J. (2001), "Holonic Assembly System with Plug and Produce", Angelkoska, S. Stankovska, G \& Dimitrovski, D. (2016). The Personal Characteristics Predictors of Academic Success. Education Provision to Every One: Comparing Perspectives from Around the World BCES Conference Books, 14(1). 262-268.

Akyol, H. (2011). Disgrafi. Eğitimci Öğretmen Dergisi, 1, 8-11.

American Psychiatric Association. (2013). Diagnostic and statistical manual of mental disorders: DSM-5. Washington, DC: American Psychiatric Association.

Bergeson, T., Davidson, C., Mueller, M., \& Williams Appleton, D. (2008). A guide to assessment in early childhood: Infancy to age eight. Office of the Superintendent for Public Instruction, Washington State. Retrieved from http://www.k12.wa.us/ Early Learning/pubdocs/assessment print.pdf.

Büttner, G., \& Hasselhorn, M. (2011). Learning disabilities: Debates on definitions, causes, subtypes, and responses. International Journal of Disability, Development and Education, 58(1), 75-87.

Classification of Diseases: ICD 10 (2015). Word Health Organization. Retrieved from https://www.who.int/classifications/icd/ICD10Volume2_en_2010.pdf.

Döhla, D. \& Heim1, S. (2015). Developmental Dyslexia and Dysgraphia: What can We Learn from the One About the Other? Front Psychol v.6. doi: 10.3389/fpsyg.2015.02045.

Duran, E. \& Karatas, A. (2019). Elimination of Writing Difficulty in Primary School: An Action Research. International Journal of Progressive Education 15(5), 288-300.

Farrall, M. L.,Wright, P. D., \& Wright, P. (2015). All about tests \& assessments: Answers to frequently asked questions. Hartfield, VA: Harbor House Law Press, Inc.

Fletcher, J. M., Lyon, G. R., Fuchs, L. S. \& Barnes, M. A. (2006). Learning disabilities: From

identification to intervention. Guilford press

Fuchs, L. S., Compton, D. L., Fuchs, D., Paulsen, K., Bryant, J. D., \& Hamlett, C. L. (2005). The prevention, identification, and cognitive determinants of math difficulty. Journal of Educational Psychology, 97(3), 493-513.

Graham, S., Santoro, J., Berninger, V.W. \& Struck, M. (2006). Dimensions of good and poor handwriting legibility in first and second graders: Motor programs, visual-spontial arrangement and letter formation parameter setting. Developmental Neuropsychology, 29 (1), 43-60. 
Hayes, A. Dombrowski, E., Shefcyk, A. \& Bulat, J. (2018). Learning Disabilities Screening and Evaluation Guide for Low- and Middle-Income Countries. U.SA. RTI Press.

Jones, C. G. (2011). Written and computer-mediated accounting communication skills: An employer perspective. Business Communication Quarterly, 74, 247-271.

Kim, Y. S., Park, C., \& Wagner, R. K. (2014). Is oral/text reading fluency a "bridge" to reading comprehension? Reading and Writing: An Interdisciplinary Journal, 27, 79-99. https://doi.org/10.1007/s11145-013-9434-7.

Kingsdorf, S., \& Krawec, J. (2014). Error analysis of mathematics word problem solving across students with and without learning disabilities. Learning Disabilities Research and Practice, 29, 66-74. doi:10.1111/ldrp.12029.

Malec, A. Peterson, S. Elshereif. H. (2017). Assessing Young Children's Oral Language: Recommendations for Classroom Practice and Policy. Canadian Journal of Education. 40(3). 362-392.

Nikolopoulos, D. (2007). [In Creek] Reading Difficulties / Dyslexia: Basic Highlights, Dilemmas and Educational Practice. In E. Botsari (ed.). School Class Problem Management. Greece: Pedagogical Institute.

Rutland, J. \& Hall, A.H (2013) Involving families in the assessment process. NHS Dialog: The Research-toPractice for the Early Childhood Field. 16 (4). 113-120. Retrieved from https://tigerprints.clemson.edu/eugene_pubs.

Scruggs, T. E., Mastropieri, M. A., Berkeley, S., \& Graetz, J. E. (2010). Do special education interventions improve learning of secondary content? A meta-analysis. Remedial and Special Education, 31, 437-449. Retrieved from https://www.tandfonline.com/doi/full/10.1080/2331186X.2016.1261568.

Tolar, T. D., Fuchs, L., Fletcher, J. M., Fuchs, D., \& Hamlett, C. L. (2016). Cognitive profiles of mathematical problem solving learning disability for different definitions of disability. Journal of Learning Disabilities, 49, 240-256. doi:10.1177/0022219414538520

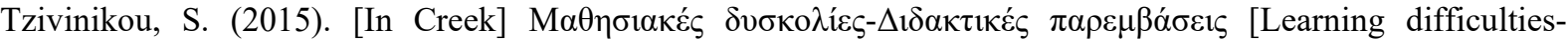
Teaching interventions]. Retrieved from: http://hdl.handle.net/11419/5332

World Health Organisation. (2008). ICD-10, International Statistical Classification of Diseases and Related Health Problems, Volume 1: Code List, Issue A. (trans. National School of Public Health). Athens: Ministry of Health \& Social Solidarity.

K. Papoutsaki studied Special Education at the National Kapodistrian University of Athens. She teaches at the Hellenic Open University and the Department of Special Education of the University of Thessaly in Greece. She has worked as a special education teacher in Primary Schools and she has been a teachers' Consultant for over 10 years. At present she is working at the Greek Public Center for Diagnosis of Learning Difficulties of Adolescents, which is housed in the National Child Hospital and is under the auspices of the National and Kapodistrian University of Athens. She has published a lot of articles and books about learning difficulties and special education.

E. Marseli is a special needs teacher in primary education. She graduated from the University of Thessaly and has been working in public special needs schools in Greece and the United Kingdom for the last nine years. She also got a bachelor degree in Psychology from the University of Hertfordshire UK. She has actively participated in many workshops and seminars as a spokesman's presenting interventions to students' behaviour in primary education, giving counsel to parents and advising teachers on how to cope and communicate to parents..

J. Papathanasiou studied Greek Literature at the University of Crete and she has got an MSc in Special Education at the Open University of Cyprus. She teaches children and adolescents with learning disabilities. She has published several articles about learning disabilities. 